\title{
A Psicologia pela lente de Renato KehI
}

\section{The Psychology by the optics of Renato Kehl}

\author{
La Psicología por la lente de Renato Kehl
}

\author{
Melline Ortega Faggion* \\ Universidade Estadual de Maringá - UEM, Maringá, Paraná, Brasil \\ Maria Lucia Boarini** \\ Universidade Estadual de Maringá - UEM, Maringá, Paraná, Brasil
}

\begin{abstract}
RESUMO
Diversos integrantes da Liga Brasileira de Higiene Mental/LBHM tiveram lugar significativo no processo de difusão e consolidação da psicologia no Brasil. A LBHM tinha como meta contribuir com a transformação do país em nação moderna a exemplo dos países europeus. Alinhados a tal proposta, tinha como principio o ideário da higiene mental e, a partir de 1928, o ideário da eugenia. Neste trabalho temos como objetivo analisar os títulos Tipos vulgares, publicado em 1927, e Psicologia da personalidade, publicado em 1941, de autoria de Renato Kehl (1889-1974), membro atuante da Liga, destacando-se sobremaneira como defensor e publicista da eugenia. Percorrendo estas obras à luz da historicidade dos fatos, observamos que os saberes psicológicos difundidos e apropriados pelo autor, referem-se a uma psicologia tida como científica, reverberada pela fisiologia experimental da psicologia europeia. Nas obras, é marcante o debate acerca do conhecimento e avaliação da personalidade para construção de uma nação forte. É igualmente marcante a concepção biologizante de homem e o caráter secundário das relações sociais na formação humana. As asserções de Kehl lançam luz às contribuições da psicologia naquela época e nos fazem refletir criticamente sobre concepções que ainda imperam no campo científico e profissional da psicologia.
\end{abstract}

Palavras-chave: personalidade, Renato Kehl, eugenia, história da psicologia.

\begin{abstract}
Several members of the Brazilian League of Mental Hygiene / LBHM had significant place in the process of diffusion and consolidation of psychology in Brazil. The goal of LBHM was to contribute to the transformation of the country into a modern nation, like the European countries. Aligned with this proposal, it had as its principle the idea ofmental hygiene and, from 1928, the ideology of eugenics. In this work, we aim to analyze the works Vulgar Types, published in 1927, and Psychology of Personality, published in 1941, by Renato Kehl (1889-1974), an active member of the League, standing out as a defender and publicist of eugenics. Going through these works in light of the historicity of the facts, we observe that the psychological knowledge diffused and appropriated by the author, refer to a psychology considered as
\end{abstract}


scientific, reverberated by the experimental physiology of European psychology. In the works, it is remarkable the debate about the knowledge and evaluation of the personality for the construction of a strong nation. It is also striking the biological conception of man and the secondary character of social relations in human formation. Kehl's assertions shed light on the contributions of psychology at that time and make us reflect critically on conceptions still prevalent in the scientific and professional field of psychology.

Keywords: personality, Renato Kehl, eugenics, history of psychology.

\section{RESUMEN}

Diversos integrantes de la Liga Brasileña de Higiene Mental/LBHM tuvieron un lugar significativo en el proceso de difusión y consolidación de la psicología en Brasil. La LBHM tenía como meta contribuir con la transformación del país en una nación moderna siguiendo el ejemplo de los países europeos. En esa línea, se fijaron como principios las ideas de la higiene mental y, a partir de 1928, el ideario de la eugenesia. Nuestro objetivo es analizar dos libros de Renato Kehl (1889-1974), miembro activo de la Liga, que se destacó sobremanera como defensor de la eugenesia. Los títulos de las obras son: Tipos vulgares, publicado en 1927, y Psicología de la personalidad, de 1941. Analizando estos textos a la luz de la historicidad de los hechos, observamos que los saberes psicológicos difundidos y apropiados por el autor, se refieren a una psicología entendida como científica e influenciada por la fisiología experimental de la psicología europea. En las obras es notable el debate acerca del conocimiento y la evaluación de la personalidad para la construcción de una nación fuerte. Es igualmente notable la concepción biologicista del hombre y el papel secundario de las relaciones sociales en la formación humana. Las aseveraciones de Kehl arrojan luz a las contribuciones de la psicología en aquel momento y nos hacen pensar críticamente sobre las concepciones que todavía imperan en el campo científico y profesional de la psicología.

Palabras-clave: personalidad, Renato Kehl, eugenesia, historia de la psicología.

\section{A historicidade dos saberes psicológicos}

A história da psicologia é analisada tendo em vista as iniciativas de personagens que participaram do seu desenvolvimento, institucionalizando os saberes psicológicos, criando laboratórios, publicando e divulgando estudos sobre psicologia, etc. Estas são formas de contar a história desta ciência e, mais que isto, representam contribuição singular para a trajetória da psicologia no Brasil.

Em que pesem as grandes contribuições de estudos no campo da história da psicologia, constituídos por uma complexidade de elementos e de condições, sua trajetória ainda se faz por conhecer. A compreensão de sua história exige de nós não somente o estudo histórico das diversas fases que constituem o corpo teórico e científico da psicologia em território brasileiro, como exige a compreensão das íntimas conexões entre as condições objetivas de 
determinadas épocas e o lugar ocupado pela psicologia naquele momento. Neste sentido, podemos falar que a psicologia já se faz presente em períodos que antecedem àquilo que entendemos e reconhecemos como ciência e profissão. Os estudos de Massimi (1990, 2004) demonstram que a propagação dos saberes psicológicos ocorreu a partir do século XVI no âmbito da filosofia, da teologia, da literatura, da medicina e da cultura brasileira.

Dentre os trabalhos produzidos no século XIX, destacamos as contribuições do médico e deputado estadual pelo estado da Bahia, Eduardo Ferreira França (1809-1857). O primeiro estudo de França foi intitulado como Essais url'influence dês aliments et dês boissons sur le moral de l'homme data de 1834. Tal trabalho tinha um caráter naturalista e buscava analisar o comportamento moral das pessoas tendo como base a alimentação. Eduardo Ferreira França acreditava que havia uma relação direta entre a alimentação e a civilização. $O$ trabalho intitulado como Influência dos pântanos sobre o homem publicado em 1850 versa sobre a influência que os alimentos e as bebidas exerciam sobre a moral dos homens, mas também, o papel dos fatores físicos no desenvolvimento do caráter. A intensa vida política de Eduardo Ferreira França no Brasil fez com que ele se dedicasse à garantia constitucional da liberdade humana, fato que se constituiu no escopo para o desenvolvimento de sua obra intitulada Investigações de Psicologia publicada em 1854. Nesta obra, o autor debate temáticas como teoria neurofisiológica da percepção, instintos, vontade, sentidos, razão, consciência, dentre outros. Eduardo Ferreira França se baseou nos métodos empíricos da ciência moderna para comprovar a existência do espírito e refutar o empirismo extremo. (Paim, 1973).

Ao longo do século XIX, a propagação dos saberes do campo da psicologia ocorreria em âmbito institucional, ou seja, foram incorporados pelos cursos de medicina, direito e educação. Para Antunes (2006), o período referente a 1890 até 1930 é reconhecido como o momento de autonomização da psicologia, momento em que a psicologia conquista sua independência como ciência em âmbito internacional, a partir da criação do laboratório experimental na Alemanha em 1879 por Wilhelm Wundt (1832-1920). No Brasil, tal autonomização coincide com fatos importantes do cenário nacional, tais como a queda do Império e, consequentemente, a implantação da Primeira República no ano de 1889. Neste período, houve iniciativas que marcaram o percurso da psicologia enquanto ciência no Brasil, a saber, a tese de doutoramento intitulada Duração dos atos psíquicos elementares nos alienados de autoria do médico Henrique Belford Roxo (1877-1969) defendida no ano de 1900 na Faculdade de Medicina do Rio de Janeiro. Este trabalho contribuiu significativamente para que a psicologia fosse associada à medição, à discriminação e ao estudo do comportamento, tendo como base o 
empirismo e os pressupostos positivistas (Alberti, 1999). A criação do primeiro laboratório de psicologia no Brasil, o Pedagogium, por iniciativa do médico e educador Manoel Bonfim (1868-1932) no ano de 1907 também é um marco nesta trajetória. A pesquisa de Maurício Campos Medeiros (1885-1966) intitulada Métodos em psicologia, publicada em 1907, e a tese de Plínio Olinto (1886-1956) Associação de ideias, publicada em 1911, são marcos importantes no desenvolvimento científico da psicologia no Brasil. (Pessotti, 1988).

Estas iniciativas e publicações, dentre outras, demonstram que os anos finais do século XIX foram significativos para o desenvolvimento da psicologia no país. A proclamação da República traria transformações no campo da educação, por meio das reformas educacionais. Uma delas foi a Reforma Benjamim Constant, que transformou a disciplina de Filosofia para Psicologia e Lógica e posteriormente a criação da disciplina Psicologia e Pedagogia. Comumente, tal reforma é mencionada no âmbito da história da psicologia devido às contribuições em sua trajetória como ciência. $O$ Movimento da Escola Nova também deu direcionamento para as reformas educacionais no país. Tal movimento tinha como fundamento os ideais burgueses norte-americanos de educação e de democracia. Partia do princípio da igualdade de oportunidades e entendia a educação como principal responsável na garantia de condições para o desenvolvimento dos indivíduos e de suas potencialidades. O movimento em tese encontrou nos conhecimentos produzidos pela psicologia subsídios para dar explicações científicas e escamotear as desigualdades sociais. (Patto, 1984).

O escolanovismo vai buscar na Europa suas origens, onde já no século anterior uma sociedade industrializada se preocupava com a individualidade do aluno. No Brasil, os pioneiros da Escola Nova defendem o ensino leigo, universal, gratuito e obrigatório, a reorganização do sistema escolar sem o questionamento do capitalismo dependente, enfatizam a importância do Estado na educação e desta na reconstrução nacional. Como solução para os problemas do país, apelam para o humanismo científico-tecnológico, ou seja, convivência harmoniosa do homem com a máquina, criando-se condições para que os indivíduos convivam com a tecnologia e a ciência, fazendo-os entender que tudo isto está a serviço e disponibilidade do homem. (Ribeiro, 1993. p. 19-20, grifo nosso).

Tais reformas contaram com os conhecimentos da psicologia para ampliar a prática pedagógica. Os estudos sobre desenvolvimento infantil e processos de aprendizagem e os testes psicológicos e 
pedagógicos converteram-se em ferramentas em prol da educação, 0 que favoreceu o avanço da psicologia no campo da ciência.

[...] a introdução da Psicologia enquanto base científica dos métodos pedagógicos, sobretudo no que diz respeito à formação dos professores nas escolas normais, propondo novos objetivos do processo educacional: não mais a formação do indivíduo conforme um ideal filosófico ou religioso, e sim sua adaptação ao ambiente, baseada na afirmação de que todo indivíduo é dono e construtor de sua própria experiência de vida e de seus princípios. (Massimi, 2004, p. 21, grifo nosso).

Ainda no tocante ao percurso histórico dos saberes psicológicos, temos nas primeiras décadas do século $X X$ a presença marcante dos médicos vinculados à Liga Brasileira de Higiene Mental (LBHM), criada no ano de 1923, na cidade do Rio de Janeiro, por iniciativa do psiquiatra Gustavo Riedel (1887-1934). Tal agremiação era composta por médicos, políticos e intelectuais da época. Os estudos desenvolvidos pelos integrantes da LBHM tinham como bandeira o ideário da higiene mental. No ano de 1929, o ideário da eugenia foi incluído no estatuto desta agremiação ${ }^{1}$ (Arquivos Brasileiros de Higiene Mental, 1929). A partir deste ano, a relação de membros da Liga que simpatizavam com o ideário da eugenia cresceu ainda mais 2 .

Lembramos que o princípio da eugenia se baseia no melhoramento moral, físico e psíquico da "raça" humana e das futuras gerações. O termo eugenia foi cunhado pelo inglês Francis Galton (1822-1911). No ano de 1883, na obra Inquiriesinto Human Faculty and its Development, o termo eugenia apareceu pela primeira vez. (Peláez, 1985). A eugenia teve sua sistematização e organização científica na Inglaterra no final do século XIX e posteriormente se propagou para outros países do mundo.

Historicamente, a ideia de raça humana esteve vinculada à superioridade entre grupos sociais. Estudos recentes no âmbito da genética indicam e comprovam a não procedência do termo raça e, portanto, sua inutilização. (Pena, 2008). O uso de tal termo no decorrer deste estudo faz menção à concepção dos eugenistas sobre raça, isto é, da ideia de "superioridade entre grupos sociais".

Em que pesem as diferenças e especificidades de cada momento histórico, é possível dizer que a preocupação com a "raça" humana alude ao contexto histórico da Antiga Grécia: isto porque filósofos, como Platão e Aristóteles, trouxeram já naquela época reflexões a respeito da importância de a sociedade ser composta por homens "robustos e saudáveis". A civilização helenística proporcionou ideias e práticas que se "assemelhavam" às discussões eugênicas do final do século XIX. (Domingues, 1942). 
Apesar da "origem" remota do aperfeiçoamento do homem, o caráter científico sobre melhoramento da "raça" foi reconhecido com os estudos de Galton. A teoria galtoniana se desenvolveu tendo como base a teoria da evolução das espécies de Charles Darwin (18091882). Tal influência permitiu que a eugenia fosse nomeada como darwinismo social (Schwarcz, 2005). Embora a proposta de aplicabilidade da teoria de Darwin no âmbito social tenha gerado intensos debates e controvérsias no campo da eugenia, o ideário ficou reconhecido como tal.

No Brasil, o ideário da eugenia teve repercussão no início do século $X X^{3}$ em um momento que o país enfrentava a crítica internacional sobre a "qualidade racial" da população local em decorrência das condições precárias do país. Com isto, desenvolveu-se um contexto favorável para ideias eugênicas no país e para uma propaganda em defesa da melhoria da "raça". A criação da Sociedade Eugênica de São Paulo ${ }^{4}$ em janeiro de 1918 pode ser vista como a materialização das iniciativas em defesa da eugenia, no Brasil.

$\mathrm{Na}$ segunda década do século XX, a atroz pobreza e a deplorável saúde dos pobres haviam se cristalizado na consciência pública como uma questão nacional - a "questão social". O grupo que mais inquietava os médicos, os especialistas em saneamento e os reformadores brasileiros, era, em sua maior parte, constituído por negros e mulatos. Esses profissionais presumiam que doenças sociais se acumulavam na base da hierarquia sócio-racial - que os pobres eram pobres porque eram anti-higiênicos, sujos, ignorantes e hereditariamente inadequados. (Stepan, 2005, p. 47)

As mazelas sociais preocupavam os integrantes da LBHM, visto que atingiam a saúde física e mental da população brasileira. Uma parte dos higienistas brasileiros acreditava que o desenvolvimento da nação dependia da atenção dispensada à saúde mental. Tal preocupação, entre outras, fez com que alguns membros da Liga, dentre eles o médico Renato Kehl (1889-1974), tomassem a eugenia como saída para tais mazelas. Ressaltamos que a adesão de medidas eugênicas não foi unânime entre os integrantes da Liga; contudo, é fato que tais ideias circulavam nos debates desta agremiação, especialmente a partir de 1929 quando foram incluídas no estatuto da LBHM, conforme citamos anteriormente. Neste cenário, o conhecimento e as técnicas produzidos pela psicologia da época eram vistos como fortes aliados em prol do desenvolvimento e cuidado da população. (Boarini, 2003).

Estudos desenvolvidos e divulgados pelos membros da LBHM foram basilares para a consolidação da ciência psicológica no Brasil. Embora esta agremiação seja referenciada como uma instituição de 
participação histórica no âmbito desta ciência, não podemos reconhecê-la como uma instituição de psicologia, visto que seus membros não a reconheciam como tal. O médico higienista Durval Marcondes (1899-1981), membro da Liga Paulista de Higiene Mental, declarou em 1979, que os higienistas "criaram oficialmente" os primeiros cargos de psicólogo(a) no Brasil. (Figueira \& Boarini, 2014). Tal declaração nos possibilita pensar na relação entre os médicos higienistas e a psicologia, mas inviabiliza que caracterizemos tal instituição como de psicologia.

Lembramos a obra de Plínio Olinto A Psicologia Experimental no Brasil, publicada em 1944 e considerada como a primeira obra sobre história da psicologia no Brasil. (Pessotti, 1988). Sem entrar no mérito desta obra, chamamos atenção para o fato de que Plinio Olinto pertencia à LBHM e seus estudos se desenvolveram na seara de discussões da higiene mental, fato poucas vezes mencionado no campo histórico da psicologia. De acordo com Figueira e Boarini (2014), produções como as de Manoel Bomfim, Plínio Olinto e Maurício de Medeiros Albuquerque são algumas, dentre outras, que podemos mencionar no campo da higiene mental e que apresentaram significativa contribuição no campo da psicologia.

Quase um século depois do movimento de higiene mental, é possível identificar as conquistas deixadas pela LBHM que foram e são reproduzidas na prática profissional do psicólogo: como exemplo, podemos citar a psicometria, amplamente utilizada e valorizada em vários campos de atuação da psicologia, com o objetivo de classificar, selecionar aptos/inaptos, avaliar desempenho, produtividade, diagnosticar, etc. Além das marcas deixadas pelo ideário higienista, a LBHM também realizou outras contribuições, como, por exemplo, as elaborações de Manoel Bomfim sobre as funções psíquicas superiores, pensamento e linguagem, em um período anterior aos grandes psicólogos soviéticos. (Figueira \& Boarini, 2014. p. 1811. Tradução nossa) ${ }^{5}$.

A busca pela superação dos problemas sociais do país no início do século XX fez com que autores supracitados, dentre outros, se dedicassem ao estudo e propostas no ramo da educação e da psicologia, isto porque, os saberes produzidos nestas áreas proporcionaram conhecimento acerca da natureza psíquica e física do homem e, por conseguinte, o tão almejado "ajustamento social". Tais estudos são comumente mencionados na história da psicologia, porém com pouco destaque ou emitidos sem vínculo com a instituição da qual eram membros ativos, ou seja, a LBHM. (Silva, 2003). O debate sobre eugenia, tema recorrente no campo da higiene mental e 
entre os integrantes da Liga, também é pouco mencionado no âmbito da psicologia.

Enfim, é fato que a temática da psicologia integrou as reflexões e discussões dos membros da LBHM e aqui se inclui os defensores da eugenia que, também, contribuíram para a divulgação do papel social da psicologia nas primeiras décadas do século XX, e, por assim dizer, fazem parte da história desta ciência.

A breve recuperação da trajetória dos saberes psicológicos ao final do século XVII e durante o século XX no Brasil nos permite afirmar que tais saberes estiveram presentes em diversos espaços e se caracterizavam como um conjunto de ideias sobre o homem, portanto, não se figuravam restritos à psicologia, mas compareciam também no campo da medicina, da educação e da filosofia. A repercussão dos saberes psicológicos em diversos campos de conhecimento nos faz reconhecer que o percurso histórico desta ciência não ocorreu de maneira linear, evolutiva e teleológica, isto é, "progredindo" com o passar do tempo. As transformações históricas destes saberes podem ser entendidas tendo em vista as condições objetivas de cada época.

\section{Eugenia e psicologia}

Haja vista a pouca notoriedade de estudos sobre a temática da eugenia na seara da psicologia, realizamos um levantamento não exaustivo, cuja finalidade era verificar os estudos sobre este assunto na psicologia. Encontramos três estudos, sendo dois de autoria de Masiero $(2005,2014)$, sobre a formação histórica de uma psicologia racial no Brasil e o conceito de psicopatologia na obra de Kehl, e a publicação de Serra e Scarcelli (2012) sobre a infância no campo da psiquiatria, tendo como base a eugenia e o higienismo, além das produções do Grupo de Estudos e Pesquisas sobre Eugenia e Higienismo (GEPHE, 1998). A despeito deste levantamento não serexaustivo e tampouco ter como objetivo levantar e analisar todas as produções sobre eugenia na psicologia, verificamos uma lacuna de estudos que versassem sobre essa temática. $O$ não reconhecimento da correlação entre eugenia e higiene mental no campo da psicologia pode ser percebido no modo como contamos a história desta ciência e, assim, indicam a relevância dos estudos que sinalizem tal correlação. Para tanto, tomamos como foco as publicações do médico Renato Kehl (1889-1974) que se constituem no cenário científico importantes defesas do ideário da eugenia e neste sentido é considerado o publicista de maior destaque sobre eugenia no Brasil.

Desta forma, temos como objetivo investigar como os saberes psicológicos integralizaram a produção Renato Kehl (1889-1974). Entretanto, no extenso rol de publicações de Renato Kehl ${ }^{6}$ abordando 
vários assuntos, elegemos como referência central as produções que versavam especificamente sobre a temática da personalidade e da psicologia. Selecionamos os títulos Tipos Vulgares, publicada em 1927 e Psicologia da Personalidade, publicada em 1941, e cujo teor abrange diretamente o campo da psicologia. Adotamos como critério de avaliação das obras as proposições de Renato Kehl acerca da formação da personalidade e, consequentemente, o modo como os conhecimentos em psicologia aparecem ao longo das duas obras. A lente teórica de análise dos materiais, bem como o modo de compreender a história, foi inspirada no materialismo histórico.

Entendemos por história o modo como os homens organizam sua existência em uma determinada época, dito de outra maneira, a história é o modo de vida produzido pelo próprio homem. Ao falarmos de produção, devemos levar em conta que o ato de produzir não se refere estritamente à produção de algo concreto, conforme indica a herança econômica conceitual do termo, mas também sua acepção filosófica, isto é, a produção relacionada à produção da ciência, das ideias, das artes, da política e etc.

A produção de ideias, das representações e da consciência está, antes de mais nada, direta e intimamente ligada à atividade material e ao comércio material dos homens; é a linguagem da vida real. [...] O mesmo ocorre com a produção intelectual, tal como se apresenta na linguagem da política, das leis, da moral, da religião, da metafísica etc., de um povo. (Ianni, 1979. p. 50).

Na obra Tipos Vulgares (1927), Kehl faz a apresentação de vinte perfis psico-críticos. O conteúdo da obra voltar-se-ia a "prevenir" e informar a população contra os "espíritos simuladores" a fim de evitar - contato com os indivíduos disgênicos (não saudável geneticamente), isto é, fora do padrão eugênico (geneticamente saudável). Um ano após publicar esta obra, Renato Kehl viaja para Alemanha. Sua estadia em território germânico teve duração de cinco meses e coincidiu com um período de vivacidade das ideias eugênicas no país. Tal fato colaborou para que o médico confiasse ainda mais na possibilidade de implementar com sucesso um projeto de melhoramento do povo brasileiro. Na esteira de estudos e debates em prol do aperfeiçoamento da "raça", Kehl se valeu do saber psicológico como uma de suas ferramentas ${ }^{7}$.

Nesta obra, o autor levanta a necessidade de estudos e observações acerca das características da personalidade dos indivíduos. Para tanto, seria necessário contar com o suporte da psico-crítica, ramo da caracteriologia. Conforme a definição de Kehl (1957), a caracteriologia é a ciência que estuda e analisa expressões psicológicas do caráter humano. 
Na obra Tipos vulgares, Kehl não trata profundamente da psicologia, mas afirma que

Em qualquer carreira profissional as possibilidades de sucesso são proporcionais à ilustração e também ao conhecimento dos homens. Não mais se compreende, portanto, o desconhecimento de noções em psicologia individual e coletiva. (Kehl, 1927, p. 17).

Ao assinalar a relevância da psicologia, Kehl pontua que a psicocrítica poderia contribuir para o conhecimento do homem, pois analisaria o psiquismo e a estrutura da personalidade de cada sujeito e tornaria possível a correção dos desvios morais. Para o autor, a obra Tipos Vulgares contribui com a "higiene moral" e se caracteriza como uma obra de psicologia prática.

É mister, por meio de uma análise psico-crítica, que não se aprende no estreito quadrante da psicologia clássica, devassar a alma dos homens. A psico-crítica com base na biologia ou mais especificamente com fundamento na constituição e temperamento torna possível compreender melhor a estrutura e dinâmica espiritual para a interpretação das indivíduopersonalidades. (Kehl, 1927, pp. 17-18).

Para Kehl, a psico-críticaera ferramenta para melhoria da população, visto que possibilitaria avaliar e caracterizar tipos "infratores dos preceitos de paz" e de "harmonia" em meio social.

Nesta obra, notamos que o autor se fundamentou em elementos de natureza psicanalítica. De acordo com Russo (2002), a entrada e difusão da psicanálise no Brasil ocorreram por meio de uma vanguarda intelectual intitulada como "grupo modernista" composta pelos psiquiatras da época, alguns eram pertencentes à LBHM, e também pela interpretação popular dessas ideias como "ferramenta de autoajuda". No campo médico, a psicanálise agregou elementos e fortaleceu o projeto de construção de uma nação moderna para ultrapassar as teorias deterministas que sentenciavam 0 desenvolvimento do país. Com isto, a psicanálise ofertou outra análise do povo brasileiro. Para Russo (2002),

[...] A civilização, a educação dos instintos e das paixões é possível. Ao mesmo tempo, é possível fazer uma releitura da questão do primitivismo na medida em que o "primitivo" é deslocado para o interior do sujeito e o evolucionismo deixa de ser pensado de modo unicamente externo, para acoplar-se a uma espécie de "evolucionismo" interno. (p. 55). 
A teoria psicanalítica de Sigmund Freud (1856-1839) é referenciada por Kehl em uma das descrições dos perfis psico-críticos especificamente no perfil castros forçados, para explicar sobre os instintos humanos. Para Kehl, o homem possui uma inclinação natural à satisfação dos instintos e as tentativas de desviarmos tal inclinação eram explicadas pelo mecanismo de sublimação. Ao falar de certos tipos vulgares, Kehl aponta para importância da educação, da higiene mental e de ações culturais realizados por médicos, psicólogos e psicanalistas.

O freudismo [a psicanálise] expondo a teoria da sublimação dos crentes que desviam para um ideal religioso obsessivo e o seu potencial genésico, não fez mais do que confirmar esta concepção etiológica do misticismo. [...] Está hoje verificado que a abstenção sexual, em grande número de indivíduos, toca profundamente o seu psiquismo, em especial a sua afetividade, criando obsessões, ansiedade e alucinações. A terapêutica indicada nestes casos pelos endocrinologistas é a simples quebra da castidade, a qual faz com que desapareçam todas estas tristes manifestações. (Kehl, 1927, pp. 152-153).

Na obra Psicologia da Personalidade, Kehl se valeu de conteúdos da psicologia e da psicanálise para compreender a formação do homem e, sobretudo, para indicar medidas necessárias em prol da melhoria da população. É importante destacar que na trajetória da consolidação da psicologia científica no Brasil os preceitos da psicanálise foram incorporados aos discursos psicológicos com 0 objetivo de esquadrinhar e adaptar o homem. (Alberti, 1999).

Embora seja notória ao longo das obras, a análise da sexualidade como uma questão primitiva dos homens, não podemos afirmar que o autor fez uso da psicanálise como alternativa para as críticas deterministas sobre a população tal como a vanguarda médica da época. Acreditamos que Kehl se baseou na psicanálise, a fim dar respostas à compreensão do ser humano, em especial para descrever e avaliar o caráter e a personalidade. Em sua produção, Renato Kehl faz defesa a uma compreensão biológica e determinista de homem, assim como expõe sua preocupação frente à degeneração do povo em decorrência da miscigenação. Deste modo, os saberes da psicanálise, bem como da psicologia, possivelmente ofereceram respaldo teórico para o desenvolvimento de teses e investigações sobre a população brasileira como também de proposições acerca da "qualidade racial" do povo brasileiro.

Quanto à obra Psicologia da Personalidade, Kehl trata de psicologia e assinala desde o princípio a importância do estudo e conhecimento em desta ciência. Além disto, avalia positivamente o fato deste campo de saber ter se transformado em um campo mais objetivo e 
prático e menos palavroso. Assim, entende como benéfica às transformações sofridas pela psicologia do campo filosófico para o âmbito instrumentalista, educacional e médica. Segundo ele, a psicologia médica

[...] indubitavelmente mais tem contribuído para remover os escombros do vetusto psicologismo intelectualista, abrindo os atuais rumos que a psico-crítica e a psicotécnica erigiram os alicerces da "psicologia da personalidade", cujo conhecimento constitui cabedal indispensável não só para os estudantes de medicina e os médicos, como para todos os que se dedicam a questões pedagógicas, de orientação técnica ou profissional, como para os administradores e o público culto em geral. (Kehl, 1957, p. 18-19)

Para o autor, a população poderia se furtar de conhecimentos de referentes à psicologia da personalidade e os benefícios que ela nos oferece e assim se refere a presente obra.

No presente trabalho não tivemos preocupações didáticas, [...] Deixamos à margem as questões ligadas aos fundamentos biológicos da personalidade, de certo modo tratados em "Sexo e Civilização" e em "Lições de Eugenia" 8 [...] para nos ocuparmos com a parte propriamente bio-social de tipos vulgares e de alguns invulgares, estes últimos a título de contraste esclarecedor. [...] Entendemos que a divulgação das mazelas do caráter, sobretudo de suas causas, resulta em benefícios de ordem profilática e terapêutica [...] Só pelo conhecimento dos defeitos próprios, dos motivos e consequências, conseguem os nossos semelhantes valer-se dos recursos indispensáveis para "melhorarem", quando "melhoráveis", e para se "curarem", quando "curáveis" (Kehl, 1957, pp. 17-18, grifo nosso).

De forma geral, apoiado na perspectiva individual e biológica, Kehl partia do pressuposto que a compreensão do homem tem como ponto de partida o próprio homem e seus atributos genéticos.

A individualidade representa o conjunto de atributos que caracterizam, fisicamente, o ser humano, enquanto a personalidade corresponde ao conjunto de atributos que 0 caracterizam psicomental e socialmente. Dentro deste critério, cabe a designação de indivíduo-personalidade ao homem total, símile de biótipo (...) com o sentido da soma das particularidades que identificam cada ser humano. (Kehl, 1957, p. 125) 
Embora o autor reconhecesse a participação do meio, de elementos sociais e educacionais no desenvolvimento humano, tais elementos não eram intrínsecos a tal processo. Sendo assim, as relações sociais, enquanto algo externo ao sujeito, contribuíam para a manifestação dos elementos hereditários.

As asserções de Kehl estiveram baseadas em conteúdos psicológicos e nos dizem muito sobre o percurso da psicologia no país nas primeiras décadas do século XX. A leitura das duas produções analisadas nos faz pensar que o médico defensor da eugenia se apropriou dos saberes psicológicos em voga na época. De acordo com Alberti (1999), ao final da segunda e início da terceira década do século XX a psicologia experimental ganhou força no Brasil e contribuiu com a separação da psicologia no campo da moral e da ética, mais articulada à filosofia, para se aproximar ao campo da experimentação, da adaptação e da comprovação ${ }^{9}$, aspecto este que pôde ser notadamente reconhecido nas obras analisadas.

\section{À guisa de conclusão}

A concepção biologicista de homem e o papel secundário das relações sociais no processo de desenvolvimento humano apresentada por Kehl reforçavam a premissa de que o entendimento adequado do sujeito deveria se concentrar, primeira e majoritariamente, nas características genéticas que o compunham para em seguida avaliar as características desenvolvidas socialmente. Sob o auspício da herança genética, não nos restaria alternativa para o projeto de melhorar e aperfeiçoar a população senão por meio dos princípios da eugenia. Desta forma, não haveria espaço para reflexões de como se dá o processo de formação humana no modo de produção capitalista. A ausência de espaço para este tipo de reflexão canaliza e enaltece ainda mais explicações individualistas sobre o homem.

O problema, pois, da subsistência, não está ligado estritamente à questão social da melhor distribuição dos bens econômicos, mas à melhor distribuição dos bens genética dos bens físicos, psíquicos e intelectuais. A situação que cada um de nós desfruta na sociedade não decorre da fortuna recebida de nossos pais, porém da nossa capacidade de conservá-la. Constitui erro atribuir todas as desgraças e injustiças sociais ao sistema denominado capitalista ou outro qualquer. Não se nega a existência de exemplos de injustiças, porém esses como exceção, e não como regra. Na distribuição de favores de que gozam alguns elementos deve-se ter em conta, sobretudo, as condições, biossociais favorecedoras e não apenas as condições 
econômicas que facultam a vitória dos mesmos. (Kehl, 1957, p. 162, grifo nosso).

Com o intuito de levar a cabo o projeto de melhoramento da "raça", Kehl se dedicou ao estudo e produção de conhecimentos que oferecesse legitimidade a esta ideia. Neste contexto, o autor se valeu dos saberes psicológicos e até mesmo dos preceitos de psicanálise. Tal fato nos faz perceber que psicologia e a psicanálise integralizaram o campo de discussões da eugenia. Os escritos de Kehl indicam a contribuição da psicologia e da psicanálise para o conhecimento dos homens. Para o médico, tais preceitos proporcionariam um maior conhecimento das características humanas, e, por conseguinte, contribuiriam com "melhoramento" do povo brasileiro e construção de uma nação "forte", pois, de acordo com Kehl (1935) os sujeitos eugênicos, ou seja, de "boa estirpe" deveriam ser estimulados à procriação, em contrapartida, dever-se-ia eliminar gradual e progressivamente os indivíduos disgênicos.

Em que pese a aproximação de Kehl à teoria psicanalítica, é necessário delinear os divergentes posicionamentos entre os preceitos eugênicos e psicanalíticos. As análises de Renato Kehl sobre o homem eram de cunho biológico e hereditário, secundarizando o papel das relações sociais no desenvolvimento humano - tal premissa não é defendida por teóricos da Psicanálise.

Lembramos ainda que entre o grupo de intelectuais simpatizantes ao ideário da eugenia, o determinismo biológico não era consensual. Embora Kehl fizesse a defesa de que todo sujeito era fruto de uma herança genética a qual não poderia sofrer alterações, as discussões sobre o melhoramento da "raça" eram atravessadas por diferentes posicionamentos. A saber, assinalamos o médico e antropólogo Edgar Roquette-Pinto (1884-1954) que apesar de apregoar as ideias eugênicas, não era favorável às medidas radicais tais como a esterilização eugênica, a substituição do povo brasileiro e a supremacia do biológico sobre o social, por esta razão defendia a educação do povo tendo em vista os princípios da eugenia. Para Roquette-Pinto,

[...] os "eugenistas apressados" - entre os quais incluía o seu colega Renato Kehl - desejavam a qualquer preço impedir a reprodução dos "fracos" e multiplicar a reprodução dos "melhores". O problema, ponderava Roquette-Pinto [...], é que, além de não se saber ao certo quais eram os "melhores", a eugenia não tinha o poder de controlar as combinações genéticas de um casal a ponto de gerar um filho perfeitamente eugênico. (Souza, 2016, p. 103). 
Haja visto que entendemos que a história se refere ao modo como os homens organizam sua existência, e isto inclui a produção de ideias e teorias, a análise da produção de um dos adeptos do ideário da eugenia nos permite verificar uma dentre as várias formas de apropriação dos saberes psicológicos da época e, deste modo, compreender a história da psicologia. Embora não possamos tecer generalizações acerca das questões sociais da época a partir dos títulos analisados, acreditamos que seus conteúdos lançam luz ao lugar da psicologia naquele momento e, portanto, devem ocupar um lugar na história desta ciência.

Neste sentido, acreditamos que a história da psicologia também pode ser contada por intermédio dos impactos da construção e apropriação desses saberes na sociedade em um determinado momento histórico. A análise das produções de um renomado defensor da eugenia no Brasil nos faz compreender o modo como homens de uma época específica organizaram sua existência e produziram ideias e teorias que oferecessem explicações sobre a realidade. Neste caso, as explicações eram de cunho biológico, individualizante e essenciais para a produção e reprodução da ordem social vigente, o capitalismo. Ao localizarmos a psicologia na seara de estudos da eugenia somos levados a refletir o papel desta ciência em um determinado momento histórico e, por conseguinte, quais foram suas transformações ao longo dos tempos.

Explicações sobre o sujeito baseadas em aspectos biológicos e descoladas de questões estruturais ainda operam, na atualidade, com muita vivacidade e se sobrepõem às explicações e análises pautadas em elementos econômicos, históricos e sociais. Tal fato mostra-se como um constante desafio no campo da produção de conhecimento e práticas críticas em psicologia. Concluímos, assim, que a compreensão sobre a difusão das ideias eugênicas no Brasil, bem como as apropriações teóricas feitas pelos intelectuais adeptos a tal ideário são importantes, pois lançam luz sobre fenômenos do presente e nos faz pensar a razão pela qual a psicologia tem sido convocada a debater e dar respostas.

\section{Referências}

Alberti, S. (1999). História da psicologia no Brasil - origens nacionais. In A. M. Jacó-Vilela, \& H. B. C. R. Jabur (Orgs.), Clio-psyché: histórias da psicologia no Brasil (pp. 237-246). Rio de Janeiro: Nape.

Antunes, M. A. M. (2006). A consolidação da psicologia no Brasil (1930-1962): sistematização de dados e algumas aproximações analíticas. Psicologia da Educação, 22(1), 79-94. 
Arquivos Brasileiros de Higiene Mental. Rio de Janeiro. (1929). Archivos Brasileiros de Hygiene Mental, 2(2), 01-03. Recuperado de http://old.ppi.uem.br/gephe/index.php/arquivos-digitalizados

Boarini, M. L. (2003). Higienismo, eugenia e a naturalização do social. In Boarini, M. L. (Org.), Higiene e raça como projetos: higienismo e eugenismo no Brasil (pp. 19-43). Maringá: EDUEM.

Domingues, O. (1942). Eugenia: seus propósitos, suas bases, seus meios (Em cinco lições). São Paulo: Companhia Editora Nacional.

Figueira, F. \& Boarini, M. L. (2014). Psicología e higiene mental en Brasil: la historia por contar. Universitas Psychologica, 13(5), 1801-1814.

Gephe (1998). Grupo de Estudos e Pesquisas sobre o Higienismo e Eugenia. Recuperado a partir de http://old.ppi.uem.br/gephe/index.php/inicio

Ianni, O. (1979). Karl Marx: sociologia. São Paulo: Ática.

Kehl, R. (1935). Lições de eugenia (2a ed.). Rio de Janeiro: Livraria Francisco Alves.

Kehl, R. (1957). Psicologia da Personalidade: Guia de orientação psicológica (7a ed.). Rio de Janeiro: Livraria Francisco Alves.

Kehl, R. (1927). Tipos Vulgares: contribuição à Psicologia prática (2 ed.). Rio de Janeiro: Francisco Alves.

Masiero, A. L. (2005). A psicologia racial no Brasil. Estudos de Psicologia, 10(2), 199-206. Recuperado de http://www.scielo.br/pdf/epsic/v10n2/a06v10n2.pdf

Masiero, A. L. (2014). A psicopatologia na obra de Renato Ferraz Kehl. Revista Interinstitucional de Psicologia, 7(2). 164-178.

Massimi, M. (2004). História da Psicologia no Brasil do século XX. São Paulo: EPU.

Massimi, M. (1990). História da psicologia brasileira: da época colonial até 1934. São Paulo: EDUC.

Patto, M. H. S. (1984). Psicologia e ideologia: uma introdução crítica à psicologia escolar. São Paulo: T. A. Queiroz.

Paim, A. (1973). Introdução. In E. F. França, Investigações de psicologia (pp. 3-52). São Paulo: EDUSP.

Peláez, R. A. (1985). Sir Francis Galton, padre de laeugenesia (Cuadernos Galileo de Historia de La Ciencia, 4). Madrid: Consejo Superior de Investigaciones Científicas, Centro de Estudios Históricos.

Pena, S. D. J. (2008). Humanidade sem raças? São Paulo: Publifolha.

Pessotti, I. (1988). Notas para uma história da psicologia brasileira. In Conselho Federal de Psicologia, Quem é o psicólogo Brasileiro? (pp. 17-31). São Paulo, Edicon/CFP. 
Ribeiro, P. R. M. (1993). História da educação escolar no Brasil: notas para uma reflexão. Paidéia (Ribeirão Preto), (4), 15-30. doi: 10.1590/S0103-863X1993000100003

Russo, J. A. (2002). A difusão da psicanálise no Brasil na primeira metade do século $\mathrm{XX}$ : da vanguarda modernista à rádio novela. Estudos e Pesquisas em Psicologia, 2(1), 53-64. Recuperado de https://www.e-

publicacoes.uerj. br/index. php/revispsi/article/view/7704/5568

Schwarcz, L. K. M. (2005). O espetáculo das raças: cientistas, instituições e questão racial no Brasil -1870-1930 (6a ed.). São Paulo: Companhia das Letras.

Serra, L. N. \& Scarcelli, I. R. (2012). Escola Pacheco e Silva: propostas para a infância paulista. In A. Mota, \& M. g. Marinho (Orgs.), História da Psiquiatria: ciência, práticas e tecnologias de uma especialidade médica ( $p p$. 191-211). São Paulo: USP, Faculdade de Medicina, Universidade do ABC: Casa de Soluções e Editora.

Silva, L. C. (2003). A contribuição da higiene mental para o desenvolvimento da psicologia no Brasil. In M. L. Boarini (Org.), Higiene e raça como projetos: higienismo e eugenismo no Brasil (pp. 133-164). Maringá: EDUEM.

Souza, V. S. (2016). A eugenia brasileira e suas conexões internacionais: uma análise a partir das controvérsias entre Renato Kehl e Edgard Roquette-Pinto, 1920-1930. História, Ciências, Saúde - Manguinhos, 23(supl.), 93-110. doi: 10.1590/s0104-59702016000500006

Stepan. N. L. (2005). A hora da Eugenia: raça, gênero e nação na América Latina. Rio de Janeiro: Fiocruz.

\section{Endereço para correspondência \\ Melline Ortega Faggion}

Rua Pires da Mota, 1011, Aclimação, CEP 01529-001, São Paulo - SP, Brasil

Endereço eletrônico: melline.ortega@hotmail.com

\section{Maria Lucia Boarini}

Universidade Estadual de Maringá

Departamento de Psicologia

Av. Colombo, 5790, CEP 87020-900, Maringá - PR, Brasil

Endereço eletrônico: mlboarini@uol.com.br

Recebido em: 18/12/2018

Reformulado em: 17/02/2019

Aceito em: 18/02/2019

\section{Notas}

* Graduada e Mestre em psicologia pela Universidade Estadual de Maringá- UEM. Pesquisadora e integrante do Grupo de Estudos e Pesquisas sobre o Higienismo e o 
Eugenismo - GEPHE. Membro da Sociedade Brasileira de História da Psicologia (SBHP).

** Psicóloga. Doutora em psicologia pela USP. Docente do Programa de pósgraduação (stricto sensu) em psicologia da Universidade Estadual de Maringá.

${ }^{1}$ A relação de membros titulares da Liga Brasileira de Higiene Mental no ano de 1929 demonstra que intelectuais que discutiam sobre a temática da eugenia eram membros da Liga. A saber, Julio Porto Carrero (1887-1937) era membro da Seção de Medicina Legal e Prevenção da Delinquência, Edgar Roquette-Pinto (1884-1954) participava da Seção de Educação e Trabalho Profissional e Renato Kehl (18891974) compunha a Seção de Medicina Geral e Especializada em suas relações com - Sistema Nervoso. O médico e professor Miguel Couto (1865-1934) fundou a Sociedade Eugênica de São Paulo juntamente com Renato Kehl e foi um dos Presidentes de Honra da LBHM.

${ }^{2}$ A saber, citamos as figuras de Juliano Moreira (1873-1932), Miguel Couto (18651934), Fernando Magalhães (187801944), Afrânio Peixoto (1876-1947), Henrique Roxo (1877-1969) e Antônio Austregésilo (1876-1960) como figuras que veiculavam suas discussões ao ideário da eugenia.

${ }^{3}$ A conferência de Renato Kehl na Associação Cristã de Moços de São Paulo em 1917 oficializa a entrada da eugenia no Brasil.

${ }^{4}$ Em 1919 a Sociedade Eugênica de São Paulo, encerra suas atividades, o que não caracteriza o fim da propaganda eugênica no país. Após o fechamento da agremiação paulistana, é possível localizar no Rio de Janeiro a criação do Boletim da Eugenia, cuja publicação ocorreu no período de 1929 a 1933.

${ }^{5}$ Casi un siglo después del movimiento de higiene mental, es posible identificar las huellas dejadas por la LBHM que fueron y son reproducidas en la práctica profesional del psicólogo: como ejemplo podemos citar la psicometría, ampliamente utilizada y valorada en varios campos de actuación de la psicología, con el objetivo de clasificar, seleccionar aptos-ineptos, medir desempeño, productividad; diagnosticar, etc. Además de las marcas dejadas por el ideario higienista, la LBHM también hizo otras contribuciones, como por ejemplo, las elaboraciones de Manoel Bomfim sobre las funciones psíquicas superiores, pensamiento y lenguaje, en un período anterior a grandes psicólogos soviéticos.

6 1) Lições de Eugenia; 2) Sexo e Civilização; 3) Tipos Vulgares, 4) Conduta; 5) Educação Moral; 6) Fada Hígia; 7) Bíblia da Saúde; 8) Porque sou eugenista; 9) Como escolher uma boa esposa; 10) Como escolher um bom marido; 11) Eugenia e medicina social; 12) Melhoremos e prolonguemos a vida; 13) Cartilha de Higiene; 14) Bio-perspectivas; 15) Livro do chefe de família; 16) Catecismos para adultos; 17) Pensamentos; 18) Psicologia da personalidade; 19) A cura da fealdade; 20) Higiene Rural; 21) Através da filosofia; 22) Médico no lar; 23) Pais, médicos e mestres; 24) Meu guia; 25) Bastomicose; 26) Perigo venéreo; 27) Envelheça sorrindo; 28) A interpretação do homem; 29) Dicionário popular de medicina de urgência; 30) Formulário da beleza.

7 Nas obras analisadas, identificamos a influência das ideias do psiquiatra alemão Enest Kretschmer (1888-1964), cujos estudos giravam em torno das classificações biotipológicas. Na obra Tipos Vulgares Kehl destaca o trabalho do médico alemão intitulado como Korperbau und charakter, de Kretschmer. Tal trabalho descreve a constituição e o temperamento de figuras famosas no âmbito da ciência.

8 Obras de autoria de Renato Kehl publicadas no ano de 1933 e 1935, respectivamente.

9 Neste contexto localizamos, por exemplo, as contribuições do psicólogo polonês Waclaw Radecki (1887-1953) no desenvolvimento da psicologia, aplicação de testes e etc.

Este artigo de revista Estudos e Pesquisas em Psicologia é licenciado sob uma Licença Creative Commons Atribuição-Não Comercial 3.0 Não Adaptada. 